ARTIGO

\title{
ANÁLISE DOS PADRÕES DISTRIBUTIVOS DA RIQUEZA NO BRASIL A PARTIR DE COMPANHIAS DE CAPITAL ABERTO - 2008 a $2016^{1}$
}

\author{
Alexandre Teixeira Norberto Batista ${ }^{2}$ \\ Wagner de Paulo Santiago \\ Luiz Antonio de Matos Macedo
}

\begin{abstract}
RESUMO
A evidenciação, por intermédio da Demonstração do Valor Adicionado (DVA), da riqueza distribuída entre as classes da sociedade promove um avanço da classe empresarial na sua relação com as demais classes, tais como Governo, financiadores externos e a população em geral. Dentro desse contexto, adotando uma investigação empírico-analítica dos relatórios contábeis de 221 sociedades anônimas, este trabalho teve como objetivo geral analisar, por meio da DVA, os padrões distributivos da riqueza gerada entre os agentes econômicos: Trabalhadores, Governo, Financiadores e Acionistas das empresas não financeiras de capital aberto brasileiras no período de 2008 a 2016. Nesta análise, ficou perceptível a relação inversa e quase simétrica (relação gráfica) entre as parcelas para capital próprio e para o capital de terceiros, principalmente. Na análise de correlações, os resultados dos coeficientes apurados respaldam estatisticamente o relacionamento entre essas variáveis, principalmente no que diz respeito à relação capital-trabalho apurada em sinal negativo com força moderada. Este estudo se faz relevante, pois combina elementos das Ciências Contábeis e das Ciências Econômicas promovendo um novo ponto de vista sobre a distribuição funcional da renda a partir das maiores companhias de capital aberto do Brasil, responsáveis por boa parte da riqueza gerada em âmbito nacional.
\end{abstract}

Palavras-chave: Demonstração do valor adicionado. Distribuição de renda. Endividamento.

\section{INTRODUÇÃO}

$\mathrm{Na}$ teoria do Desenvolvimento Econômico, encontra-se a tarefa de explicar, macroeconomicamente, as causas e o mecanismo do aumento da produtividade do fator trabalho e suas repercussões na organização da produção e na distribuição do produto social criado. Não existe desenvolvimento sem que o produto e a renda média cresçam; porém, dentro de uma perspectiva histórica, as críticas sobre esse processo são inúmeras

\footnotetext{
${ }^{1}$ Como citar este artigo: BATISTA, Alexandre Teixeira Norberto; SANTIAGO, Wagner de Paulo; MACEDO, Luiz Antonio de Matos. Análise dos padrões distributivos da riqueza no Brasil a partir de companhias de capital aberto - 2008 a 2016. ForScience: revista científica do IFMG, Formiga, v. 7, n. 1, e00607, jan./jun. 2019. DOI: 10.29069/forscience.2019v7n1.e607.
}

${ }^{2}$ Autor para correspondência: Alexandre Teixeira Norberto Batista. E-mail: alexandretnb@yahoo.com.br. 
(FURTADO, 1961; BRESSER-PEREIRA, 2006). Em vista disso, as empresas, principais responsáveis por articular a geração de riqueza do país e, assim, elementos fundamentais ao desenvolvimento econômico, passaram a ser cobradas em relação ao seu comprometimento e responsabilidades para com a sociedade e o meio ambiente.

Dessa forma, emerge uma nova relação da classe empresarial com os stakeholders que abre espaço para o desenvolvimento de uma vertente de estudos e pesquisas, proporcionados por informações que, anteriormente, eram omitidas pelas empresas, pois se dava maior enfoque aos detentores do capital.

Informações desse cunho podem ser obtidas na Demonstração Contábil do Valor Adicionado (DVA), objeto de análise deste estudo, sendo esta a demonstração contábil que evidencia a riqueza criada pela empresa e a distribuição dessa riqueza aos vários agentes econômicos que contribuíram para essa criação.

A partir de meados dos anos 1970, a DVA foi incorporada por grandes empresas europeias, inicialmente de forma voluntária em seus relatórios anuais (MORLEY, 1979). No entanto, no Brasil, a adoção da DVA como um instrumento de análise tem seu pioneirismo com estudos e pesquisas realizadas no Departamento de Contabilidade e Atuária da Faculdade de Economia, Administração e Contabilidade da Universidade de São Paulo (FEA-USP) (TINOCO, 1984; DE LUCA, 1991, 1996; SANTOS, 1999; CUNHA, 2002). Tais estudos foram realizados em um momento no qual a DVA ainda não era uma demonstração compulsória. Desde então, estudos teóricos e empírico-analíticos utilizando a DVA como instrumento de pesquisa vêm se popularizando no meio acadêmico, mas, até o presente momento, ainda contribuem de forma tímida para o estado da arte.

O marco definitivo da instauração desse instrumento no Brasil deu-se com a publicação da Lei 11.638, de 28 de dezembro de 2007, que altera e revoga dispositivos da Lei $\mathrm{n}^{\circ}$ 6.404, de 15 de dezembro de 1976, e da Lei ${ }^{\circ}$ 6.385, de 7 de dezembro de 1976. Entre outras importantes alterações, instituiu às empresas de grande porte a obrigatoriedade da elaboração e da divulgação da DVA a partir do ano de 2008. Assim, de maneira oportuna, esse ano será o ponto de partida para as análises que serão aqui delineadas.

De maneira geral, a DVA é dividida em duas partes, as quais, em um primeiro momento, mostra o quanto a empresa agrega de valor aos insumos adquiridos de terceiros, evidenciando, de fato, o Valor Adicionado (VA) daquela instituição. Em sua segunda parte, é mostrado a quem pertence a riqueza criada pela empresa, ou qual destino foi dado a essa riqueza na forma de distribuição aos agentes econômicos: trabalhadores, governo, financiadores e acionistas. 
Boa parte das linhas de pesquisa relacionadas a este tema segue essas duas vertentes da referida demonstração - ora se concentra na evidenciação do valor adicionado e a sua relação com o Produto Interno Bruto (PIB) (DE LUCA, 1996), ora tem seu foco voltado para a distribuição da riqueza aos agentes que auxiliaram na sua criação (SANTOS, 1999; CUNHA, 2002; WINK, 2014). As pesquisas também podem se restringir a evidenciar apenas uma parcela do valor adicionado distribuído, como em Moraes (2008), que teve seu foco em aferir a carga tributária das empresas brasileiras e, por essa perspectiva, estabeleceu uma nova finalidade para esses estudos. Com o melhor entendimento da DVA proporcionado pelos trabalhos desenvolvidos, foi possível, ainda, questionar a verdadeira natureza de determinadas contas que a compõem (FREGONESI, 2009). Nessa última linha, um estudo mais recente explora a DVA para sugerir um modelo alternativo desta que evidencie, de maneira mais eficiente, o impacto econômico e social de cooperativas agropecuárias (LONDERO; BIALOSKORSKI NETO, 2016).

À medida que as pesquisas avançam nessa área, surgem novas vertentes de estudos e, concomitantemente, manifesta-se a sofisticação metodológica para análise de resultados em abordagens empírico-analíticas (SCHERER, 2006; MACHADO, 2010; VIEIRA, 2010). Essas pesquisas tomam por base as predições testáveis levantadas em pesquisas teóricas sobre o tema.

A má distribuição de renda é um dos principais entraves ao desenvolvimento econômico, observada principalmente nos países subdesenvolvidos, uma vez que o acúmulo de capital cresce em níveis superiores à renda per capita (BRESSER-PEREIRA, 2006). Estudos que analisam esta questão, em sua maioria, têm como base os dados fornecidos pelo Sistema de Contas Nacionais (SCN), a partir de levantamentos estatísticos (HALLAK NETO; SABOIA, 2014). Novas fontes de dados como aquelas originadas dos relatórios contábeis, poderiam ser bem-vindas e utilizadas na construção de estudos dessa linha, com finalidade de "elaborar e usar estatísticas da renda nacional” (CPC 00, 2011, p. 03)

Dentre os males que assolam o desenvolvimento da economia no Brasil, desta vez, em um cenário recente de crise econômica, está o endividamento excessivo por parte das maiores companhias nacionais de capital aberto, levando-as a uma "asfixia financeira" (FRAGA; CARNEIRO, 2016). A consultoria Economatica ${ }^{\circledR}$ (2017) apurou a evolução do endividamento bruto de 261 companhias, com dados disponíveis na Comissão de Valores Mobiliários (CVM), e apontou que elas atingiram endividamento recorde no período, saindo de $\mathrm{R} \$ 531$ bilhões em 2010 para $\mathrm{R} \$ 1,35$ trilhões em 2015, registrados no terceiro trimestre desse último ano. 
A conjuntura econômica atual enseja uma mudança nas proporções da destinação do valor agregado das empresas, comparativamente a um passado não tão distante em que o país vivenciou crescimento e prosperidade econômica, contribuindo para que essas companhias se alavancassem por meio de captação de recursos de terceiros, que, agora, devem ser pagos em um cenário de redução de receitas e lucros, consequentemente. Seria esse, então, um momento conveniente para se analisar como se comportaram ao longo do tempo as variações da distribuição da riqueza entre os agentes beneficiários desta, uma vez que um maior peso em termos de distribuição para um lado acarretaria uma redução para as demais partes.

A partir das informações contidas na DVA, que passou a ter maior disponibilidade a partir do ano de 2008, e da busca de uma contribuição para que esse instrumento se torne uma ferramenta de auxílio em análises macroeconômicas, com o fornecimento de informações complementares ao que já é utilizado, além de se tornar uma fonte de informações aos governantes e responsáveis pela elaboração de políticas públicas para avaliação das relações sociais, delimita-se a questão-problema que norteou o desenvolvimento desta pesquisa: quais foram os padrões de comportamento da riqueza distribuída aos agentes econômicos a partir da análise das DVAs de empresas não financeiras de capital aberto no Brasil, no período de 2008 a $2016 ?$

Sendo assim, esta pesquisa teve como objetivo analisar, por meio da Demonstração do Valor Adicionado, os padrões distributivos da riqueza gerada entre os agentes econômicos trabalhadores, governo, financiadores e acionistas das empresas não financeiras de capital aberto brasileiras no período de 2008 a 2016.

\section{REVISÃO DA LITERATURA}

\section{1 Evidências empíricas}

Ao passo que avançam os meios de comunicação, a estrutura legal do país e a visão das empresas quanto ao seu disclosure, começam a se tornar possíveis e mais recorrentes as pesquisas e trabalhos envolvendo informações fornecidas pelas empresas.

Com base nessa evidência, Lorandi e Alexandre (2011) realizaram um estudo bibliométrico buscando identificar o perfil dos artigos publicados em revistas nacionais disponibilizadas no sítio da Coordenação de Aperfeiçoamento de Pessoal de Nível Superior (CAPES) que tiveram como foco principal a DVA. Os autores identificaram 14 artigos publicados sobre o tema no período de 1992 a 2007, com o enfoque predominantemente 
empírico para a maioria dos artigos. A maior parte dos trabalhos objetivou avaliar a distribuição da riqueza aos agentes econômicos dentro de um setor específico, com prevalência do setor elétrico, e nenhum com enfoque no setor de serviços. Constatou-se, também, a superioridade do governo no recebimento do valor adicionado.

Nesse estudo, apesar da predominância de autores brasileiros, percebem-se também alguns autores estrangeiros citados nos trabalhos. Constatou-se que o desenvolvimento de pesquisas no ramo ainda se encontra de forma tímida, apesar das pesquisas sobre DVA, no Brasil, terem começado a ser exploradas nos anos 1980, com Alberto Almada Rodrigues, em 1981, segundo Tinoco et al. (2011), seguido do próprio Tinoco, em 1984, em sua dissertação de mestrado.

Ainda nessa linha, Teodoro et al. (2012) realizaram um estudo semelhante cujo objetivo foi verificar, em pesquisas científicas, as tendências gerais, metodológicas e temáticas relacionadas ao valor adicionado e à DVA. Identificaram que pesquisas positivas e empíricas correspondem à maior parte dos estudos desenvolvidos nessa vertente - algo que não é incomum em se tratando de pesquisas em contabilidade e finanças. Outra constatação dos autores diz respeito à concentração considerável de estudos dessa natureza no domínio da Fundação Instituto de Pesquisas Contábeis, Atuariais e Financeiras (FIPECAFI), justificada pela sua posse do banco de dados destinado à classificação das maiores e melhores empresas pela Revista Exame.

A exemplo de utilização da DVA como uma ferramenta capaz de aferir a riqueza gerada pelas empresas e a sua distribuição aos agentes econômicos, Cunha (2002), em sua dissertação de mestrado e, posteriormente, Cunha, Ribeiro e Santos (2005), em formato de atualização, realizaram seu estudo a partir das demonstrações de 416 empresas, no período de 1999 a 2003. Em seus resultados, constataram que o governo, por meio dos impostos recolhidos, ficou com a maior fatia de distribuição do DVA, perdendo para os financiadores externos no ano de 1999 apenas. Outra observação desses autores foi a relação negativa existente entre o número de empregados contratados e a evolução das despesas com estes, bem como a relação negativa entre o valor adicionado total e o valor distribuído aos trabalhadores, uma vez que, quando o primeiro aumenta, o segundo tende a sofrer reduções. Dessa forma, demonstraram a capacidade da DVA como um bom instrumento avaliador da distribuição da riqueza gerada pelas empresas.

Em outra vertente, o estudo de Vieira (2010) buscou "desmitificar" premissas falaciosas mantidas na literatura a respeito do valor adicionado e, para alcançar seus objetivos, testou algumas hipóteses empregando testes estatísticos de correlação, teste de médias e 
modelos lineares generalizados. As premissas levantadas puderam ser testadas a partir de informações extraídas das DVAs de diversas empresas, mantidas no banco de dados da FIPECAFI no período de 2004 a 2009. Esse trabalho de Vieira (2010), apesar de se assemelhar em partes com este estudo no que diz respeito a algumas métricas estatísticas aplicadas (de correlação), não teve o objetivo de avaliar a evolução da riqueza gerada pelas empresas selecionadas ao longo do tempo, como outros estudos nesta linha.

Mais adiante, Scarpin et al. (2012), a partir das predições dos estudos anteriores, investigaram a correlação existente entre o valor adicionado distribuído aos trabalhadores e a lucratividade das empresas. Constataram que existe forte correlação entre as variáveis selecionadas, em que o setor de "atacado" apresentou a maior correlação dentre os setores analisados.

A utilidade da DVA, quanto às informações prestadas aos stakeholders, tem se tornado cada vez mais importante no Brasil. Nesse aspecto, Machado (2010), por meio da análise de conteúdo de questionários aplicados e regressão logística, buscou averiguar a percepção dos usuários externos dos relatórios anuais das empresas em relação à qualidade das informações sociais e ambientais neles contidas. Foram encontradas perspectivas divergentes entre os usuários "representantes de empresas de capital aberto", "analistas credenciados na CVM" e "acadêmicos de pós-graduação em Ciências Contábeis".

Outra vertente de utilização da DVA, como objeto de pesquisa, é para aferição da carga tributária suportada pelas empresas (SANTOS; HASHIMOTO, 2003; MORCH et al., 2008; TINOCO et al., 2011; SILVA; MARQUES, 2015). As pesquisas visam evidenciar a carga tributária das empresas por um enfoque setorial, podendo ser comparada com a carga tributária no Brasil medida pelo Instituto Brasileira de Geografia e Estatística (IBGE). Ainda, mostram como a medição e a análise da carga tributária teriam vantagens se calculadas por setores ou segmentos da economia, e não como uma média nacional geral, por meio da divisão dos tributos arrecadados nos níveis governamentais e em relação ao Produto Interno Bruto (PIB).

Santos et al. (2013) inseriram a discussão no cenário político ao realizarem um estudo objetivando identificar o comportamento da riqueza criada pelas empresas e sua distribuição, comparativamente nos governos Fernando Henrique Cardoso (FHC) (1995-1998 e 19992002) e Luís Inácio Lula da Silva (Lula) (2003-2006 e 2007-2009). Estudos nesse sentido podem demonstrar possíveis fatores determinantes do Valor Adicionado das empresas e sua distribuição a partir das políticas governamentais. 
Um estudo mais recente de Machado, Macedo e Machado (2015) buscou analisar a relevância do conteúdo informacional (value relevance) da DVA no mercado de capitais brasileiro, identificando se existe relação entre o preço das ações no mercado e a riqueza criada por ação. Além disso, objetivou verificar se este último indicador representa uma melhor proxy explicativa para o resultado que o lucro líquido por ação.

Motivados por alguns apontamentos de Fregonesi (2009), Londero e Bialoskorski Neto (2016) propuseram modificações quanto ao disclosure da DVA especificamente para cooperativas agropecuárias, tendo em vista particularidades das sociedades cooperativas. Os autores constataram que o impacto econômico e social das cooperativas, principalmente na esfera local, onde atuam, pode ser melhor evidenciado a partir da DVA. Esse estudo incentiva a prática da contabilidade específica a segmentos com características distintas das empresas em geral.

Na medida em que se dão os avanços nas pesquisas acerca do tema, desenvolvem-se também sofisticações metodológicas e novas linhas de pesquisas para compor as ramificações criadas pelos pioneiros na área. Com o marco da Lei 11.638/07, que torna compulsória a divulgação da DVA por empresas de capital aberto, espera-se que essas pesquisas venham a se desenvolver ainda mais, já que esses dados se tornaram públicos.

\section{METODOLOGIA}

\subsection{Identificação, coleta e filtragem dos dados}

No que concerne à amostra dos dados, foram delimitadas as empresas não financeiras com ações negociadas na B3 e com sede no Brasil que publicaram demonstrações em 2008 e que mantiveram seu registro ativo na bolsa ao longo do período estudado (de 2008 a 2016). Para o levantamento, organização e filtragem das empresas aptas a realização deste estudo, bem como para identificar sua classificação setorial e dados cadastrais, foi utilizada a base de dados consolidados Economatica ${ }^{\circledR}$. O critério básico para a seleção das empresas foi a publicação de demonstrativos em todos os anos estudados, para fins comparativos ao longo de todo o período.

As empresas do setor financeiro foram excluídas da amostra, assim como as Holdings puras, em função da sua natureza de participações em várias empresas, de setores também diversificados. Outras empresas também foram excluídas por publicarem demonstrações em exercício que difere do ano fiscal das empresas em geral. 
Feitas as devidas filtragens, chegou-se a 221 empresas que entregaram suas demonstrações em todos os anos do período e, assim, a um total de 1989 observações.

Em seguida, para a extração dos dados das DVAs das empresas selecionadas, foi utilizada a base de dados de Demonstrações Financeiras Padronizadas (DFP), dessas empresas no domínio da CVM, buscando nas DVAs consolidadas - caso houvesse - as seguintes contas, em cada ano: 7.07 Valor Adicionado Total a distribuir; 7.08.01 Pessoal; 7.08.02 Impostos, Taxas e Contribuições; 7.08.03 Remuneração de Capitais de Terceiros; 7.08.04 Remuneração de Capitais Próprios; 7.08.05 Outros.

Assim, essas contas representam as variáveis que foram analisadas neste estudo, tanto em valor absoluto (forma em que foram extraídas das DFP) quanto em percentual do valor adicionado correspondente à cada distribuição (dividindo-se a conta da distribuição pelo VA), como sugerem Martins, Miranda e Diniz (2018). Outras variáveis que também foram incluídas são as participações do valor adicionado no PIB, que mostra a representatividade do VA dessa amostra de empresas na riqueza total gerada, e a participação do valor adicionado na receita operacional líquida, que representa o percentual da receita que foi convertida em VA, conforme apresentadas também por Cunha (2002) e Cunha, Ribeiro e Santos (2005). Ressalta-se que todos os valores monetários apurados aqui foram coletados em valor nominal (tanto os dados das empresas quanto o PIB), atualizados pelo Índice de Preços ao Consumidor Amplo (IPCA) para 31-12-2016, estando, assim, todos referenciados nessa mesma data para as devidas análises e comparações.

\subsection{Tratamento dos dados}

A base de dados foi organizada, tabulada e tratada estatisticamente por meio da planilha Microsoft Excel®. A priori, com os dados compilados, aplicaram-se as estatísticas descritivas para a organização, sumarização e descrição detalhada desse conjunto de dados, por meio de medidas de posição central, ordenamento e dispersão (MARTINS; THEÓPHILO, 2016). Para avaliar o grau de associação linear entre as variáveis analisadas, foram estimados coeficientes de correlação de Pearson, compondo uma de uma matriz de correlação.

\section{RESULTADO E DISCUSSÃO}

\subsection{Estatísticas descritivas gerais}


Na Tabela 1, são apresentadas as estatísticas descritivas para os dados das empresas e seus resultados de valor adicionado, bem como as distribuições aos agentes, dentro do período estudado:

Tabela 1 - Estatísticas descritivas dos resultados de valor adicionado e sua distribuição. Empresas de capital aberto com sede no Brasil - 2008 a 2016

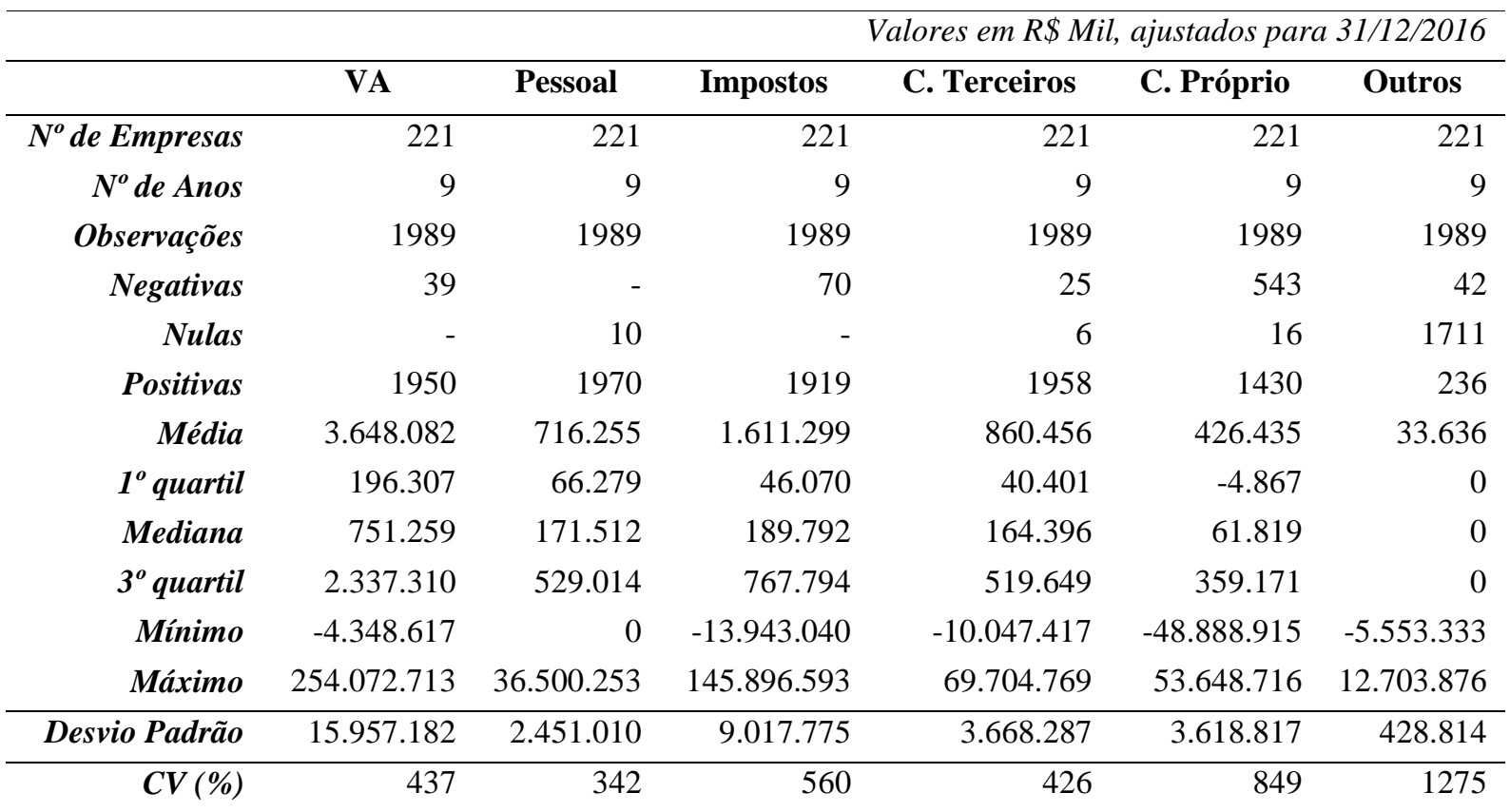

Fonte: Autores.

A análise das empresas, ao longo dos anos, abrangeu 1989 observações para cada variável estudada. Dessas observações, no que tange ao valor adicionado, 39 corresponderam a publicações de valores negativos pelas empresas. Já com relação à distribuição do VA, apenas a distribuição para Pessoal não apresentou valores negativos, o que é coerente com a realidade para essa categoria. As distribuições negativas ao Capital Próprio são as mais representativas de todas as classes, chegando a acontecer 543 vezes. Isso se deve, em grande medida, aos prejuízos acumulados pelas empresas durante o período.

No que tange às observações nulas, para o VA, isso não seria possível em empresas ativas. Da mesma forma, essas empresas não estão isentas de pagar impostos, justificando a nulidade para essa classe. De forma atípica, 10 publicações nulas na distribuição para pessoal foram observadas. Essas observações estão concentradas em duas empresas e são incomuns para essa classe. Provavelmente esse fato se deve à contratação de pessoal terceirizado, que pode não ser considerado como parte da distribuição do VA.

Com relação à distribuição para "Outros", a maioria das empresas não reconhece essa categoria dentre as demais, resultando em 1711 observações nulas. De fato, teoricamente, ela 
não deveria existir, visto que os valores alocados nesse item deveriam se encaixar em alguma das demais classes de distribuição, a não ser em caso de Royalties e outros direitos de propriedade. Apenas 56 empresas, ou o equivalente a $25 \%$ da amostra, publicaram valores destinados a esse item. Além disso, vale ressaltar que $65 \%$ do total dos valores distribuídos a Outros, em todo o período, estão concentrados em cinco empresas e, em vista disso, esse item não terá o mesmo tratamento comparativo entre os agentes econômicos nas análises que seguem.

Dando sequência aos cálculos das estatísticas descritivas, para o VA, obteve-se uma média de, aproximadamente, $\mathrm{R} \$ 3,65$ bilhões e a mediana de $\mathrm{R} \$ 725$ milhões. Uma vez que a média é superior à mediana calculada, percebe-se que valores extremamente altos estão interferindo no cálculo da média, "puxando-a para cima". Essa questão pode ser confirmada pelos valores de máximo e mínimo apurados, de R\$ 254 bilhões e R \$ -4,35 bilhões, respectivamente, ambos bem destoantes do comportamento médio, porém, com maior destaque do primeiro. Os valores de máximo apurados, para todas as categorias, são oriundos da Petrobrás, que, sozinha, produziu $27 \%$ do valor adicionado da amostra.

A dispersão com a qual os dados se apresentam foi medida pelo desvio padrão, que se apresentou em R $\$ 16$ bilhões, indicando valores bastante dispersos com relação à média. Por sua vez, o coeficiente de variação, ou desvio padrão relativo, reforça, em uma medida relativa, o patamar de variação padrão das observações em $437 \%$. Isso se explica pela diversidade de setores e empresas na composição da amostra. Assim, as informações obtidas nas estatísticas descritivas corroboram para a existência de assimetria na distribuição dos dados, considerando a análise geral das empresas.

\subsection{Evolução do valor adicionado e sua distribuição aos agentes econômicos}

Na sequência, é realizada uma análise do valor adicionado e da sua distribuição aos agentes econômicos, relativa à sua evolução e representatividade ao longo dos anos. A soma do valor adicionado das 221 empresas, ajustado pela inflação, junto da sua participação no PIB e no agregado da receita líquida operacional, bem como as parcelas de distribuição aos agentes econômicos, são especificadas para cada ano do período na Tabela 2. 
Tabela 2 - Valor Adicionado e sua participação (\%) no PIB e na Receita das empresas, e sua distribuição aos agentes econômicos. Empresas de capital aberto com sede no Brasil - 2008 a 2016

\begin{tabular}{llllllllll}
\hline & & & & \multicolumn{5}{c}{ Valores em $R \$$ mil, ajustados para $31 / 12 / 2016$} \\
\hline Ano & VA & \%PIB & \%Rec & & Pessoal & Impostos & C. Terceiros & C. Próprio & Outros \\
\hline $\mathbf{2 0 0 8}$ & 774.347 .803 & 15,1 & 56,0 & & 15,5 & 44,3 & 18,7 & 18,9 & 2,5 \\
$\mathbf{2 0 0 9}$ & 725.532 .865 & 13,8 & 56,9 & & 17,5 & 45,6 & 14,4 & 21,6 & 0,9 \\
$\mathbf{2 0 1 0}$ & 837.068 .213 & 14,4 & 55,3 & & 17,4 & 43,8 & 14,7 & 23,5 & 0,6 \\
$\mathbf{2 0 1 1}$ & 900.537 .258 & 14,7 & 54,6 & & 17,7 & 42,7 & 19,3 & 19,6 & 0,6 \\
$\mathbf{2 0 1 2}$ & 820.985 .826 & 12,9 & 47,0 & & 20,8 & 45,2 & 21,3 & 10,9 & 1,8 \\
$\mathbf{2 0 1 3}$ & 834.296 .338 & 12,5 & 47,8 & & 21,3 & 43,5 & 24,0 & 10,2 & 1,1 \\
$\mathbf{2 0 1 4}$ & 754.535 .253 & 11,1 & 41,8 & & 23,6 & 44,6 & 27,3 & 3,7 & 0,7 \\
$\mathbf{2 0 1 5}$ & 810.804 .216 & 12,7 & 47,1 & & 21,4 & 43,0 & 44,2 & $-8,8$ & 0,1 \\
$\mathbf{2 0 1 6}$ & 797.927 .592 & 12,7 & 50,4 & & 21,5 & 45,1 & 28,3 & 5,1 & 0,1 \\
\hline Média & 806.226 .152 & 13,3 & 50,8 & & 19,6 & 44,2 & 23,6 & 11,6 & 0,9 \\
\hline
\end{tabular}

Fonte: Autores.

Observou-se uma alternância entre crescimento e declínio no período em questão, com maiores tendências de alta nos anos de 2010 e 2011, em que se alcançou os maiores picos na somatória da amostra para cada ano, com crescimento de $15,37 \%$ e $7,58 \%$, respectivamente. Entretanto, no ano de 2012, o VA sofreu declínio correspondente a -8,83\%. A partir de então, nos anos subsequentes, os resultados passaram a se alternar, com 1,62\%, $-9,56 \%, 7,46 \%$, $-1,59 \%$, para 2013, 2014, 2015, 2016, respectivamente. Além disso, percebeu-se que o crescimento do VA, no período, não conseguiu acompanhar o crescimento do PIB; como se nota no quociente “\% PIB”, sua representatividade tem menores proporções ao longo do tempo, mesmo no cenário de estagnação e recessão econômica dos últimos três anos do período, em que o PIB teve decréscimo. Cabe aqui ressaltar a representatividade do valor adicionado dessas empresas sobre o PIB, que foi de $13 \%$ em média do período. Essa é uma fatia bastante expressiva e mostra a capacidade de geração de riqueza das empresas contidas nesta amostra, constituída pelas maiores sociedades anônimas de capital aberto do Brasil.

Com relação ao quociente de participação do valor adicionado na receita, "\% Rec", constatou-se que essas empresas vêm reduzindo a capacidade de transformar receita em VA, e isso corrobora diretamente com a queda da sua participação na formação do PIB, pois reflete uma perda na eficiência, em média, de agregar valor aos insumos (bens e serviços) adquiridos de terceiros. A respeito desses insumos, a título de exemplo, o País vivenciou aumentos consecutivos na tarifa média de energia elétrica, com destaque para o ano de 2015, em que houve um aumento de 43\%, segundo a Empresa de Pesquisa Energética (EPE) (2016), vinculada ao Ministério de Minas e Energia. Esse fato, de certa forma, influenciou a capacidade das empresas na conversão de suas vendas em VA. Com isso, vale lembrar que 
esta é uma análise das empresas em geral, e tais participações terão mudanças significativas se analisadas por setor econômico.

Em especial, o ano de 2014 merece destaque por ser o que mais contribuiu para o baixo crescimento do período. Tanto a participação do VA no PIB quanto a participação do VA na receita foram as menores. Entretanto, a geração de receita dessas empresas, em 2014, em reais, de 31/12/2016, foi a maior de todo o período, no patamar de aproximadamente $\mathrm{R} \$$ 1,8 trilhões, 3,5\% a mais que no ano anterior. Esses resultados sugerem ineficiência das empresas, no ano em questão, em agregar valor aos seus bens e serviços produzidos, possivelmente ligada a fatores exógenos a essas organizações. Em vista disso, cabe destacar que a relação de representatividade do VA das empresas no PIB pode ser avaliada, conforme a Equação (1), pela seguinte identidade:

$$
\frac{V A}{P I B} \equiv \frac{V A}{R E C} \times \frac{R E C}{P I B}
$$

De forma prática, percebe-se que variações na receita gerada poderiam influenciar a participação do VA das empresas no PIB. No caso das empresas da amostra, observou-se que a representatividade da receita no PIB, segundo quociente do lado direito da identidade acima, permaneceu praticamente constante, com variação pouco dispersa. Esse fato fornece evidência de que, neste caso, o principal fator que contribuiu para a redução do VA são componentes intermediários, situados entre a geração de receita dessas empresas até a formação do seu valor adicionado.

Já na segunda parte da Tabela 2, tem-se a evolução do valor adicionado distribuído aos agentes econômicos em termos percentuais, em cada ano do período analisado. Nesse intervalo, somente a distribuição ao capital próprio apresentou evolução negativa.

A apropriação da riqueza pelos trabalhadores, na forma de salários, encargos e benefícios, permaneceu em um patamar em torno de 17,5\%, até o ano de 2011, e teve um "salto" em 2012 para 21\%, até o ano de 2014, em que atingiu o seu ápice, com participação de $24 \%$ do total, aproximadamente. A partir de então, apesar de queda em 2015, ainda manteve consistência, considerando sua evolução no período, mantendo-se em terceiro lugar na distribuição, com média de 20\%. Estas apurações diferem dos resultados dos trabalhos de Cunha (2002) e Cunha, Ribeiro e Santos (2005), que analisaram a distribuição do VA de 198 e 416 empresas, respectivamente, porém para períodos anteriores. Em seus estudos, a 
participação dos trabalhadores na riqueza gerada decresce consideravelmente ao longo dos anos que estudaram, enquanto esta última aumenta.

A distribuição por meio dos impostos, taxas e contribuições pagos ao governo se consagra, de maneira geral, em primeiro lugar na distribuição da riqueza, com média de $44 \%$ no período, sem oscilações significativas. Entretanto, no ano de 2015, a distribuição ao Capital de Terceiros supera, de forma sutil, a distribuição ao governo, ocupando a primeira colocação nesse ano. Essa mesma superação é constatada por Cunha, Ribeiro e Santos (2005) no ano de 1999, para as empresas da sua pesquisa.

A participação do Capital de Terceiros, constatada neste trabalho, referente aos pagamentos de juros e aluguéis aos financiadores externos de capital, é a categoria da distribuição da riqueza que mais evoluiu no período, com grandes variações, chegando a representar $44 \%$ em 2015. Sua participação na média do período foi de $24 \%$, o que lhe concede o segundo lugar em termos de apropriação da riqueza distribuída. Porém, diferentemente dos impostos pagos ao governo, o VA distribuído a terceiros apresenta maior variação ao longo período.

Por sua vez, a participação do Capital Próprio, representada por valores distribuídos aos sócios e acionistas, bem como os lucros (ou prejuízos) retidos pelas empresas, teve comportamento inverso em relação às demais classes, com declínio e maior variação ao longo do período. Com média de participação no VA em $12 \%$, classifica-se na quarta posição na apropriação da riqueza distribuída. A distribuição ao Capital Próprio passa de segundo lugar, nos 4 primeiros anos do período, para a quarta posição, a partir do ano de 2012, e se mantém nessa colocação. No ano de 2015, sua participação foi negativa em 8,8 pontos percentuais, influenciada pela crise, com prejuízos acumulados naquele ano.

Essa constatação também se mostrou diferente dos resultados apurados em Cunha (2002) e Cunha, Ribeiro e Santos (2005) para períodos anteriores, e, dessa forma, pode-se dizer que o comportamento da distribuição do VA mostra-se bastante sensível no decorrer do tempo, à evolução da conjuntura econômica, com exceção da distribuição ao governo, que se mantém no mesmo patamar desde os estudos anteriores, numa análise das empresas em geral.

A forma como se comportou a distribuição da riqueza aos agentes econômicos pode ser melhor visualizada e sumarizada no Gráfico 1, a seguir, que mostra como foi sua evolução ao longo dos anos. 


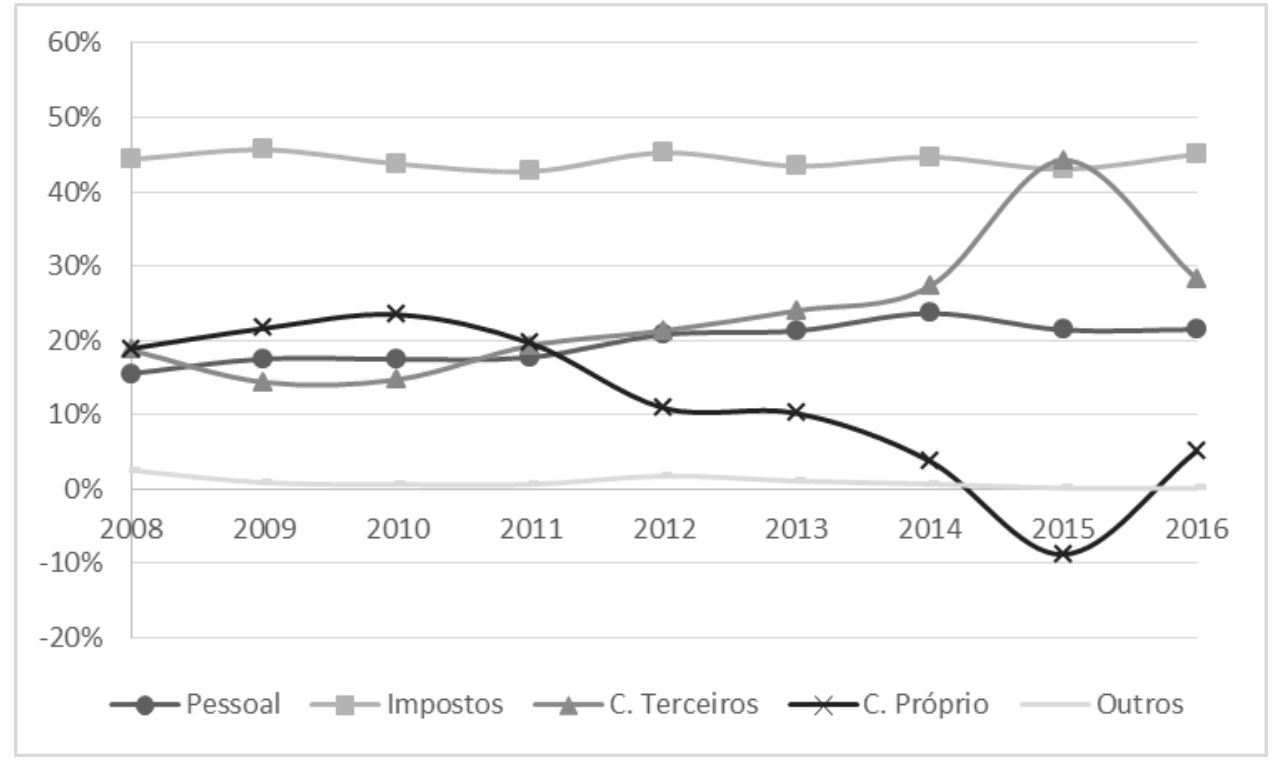

Gráfico 1 - Evolução da distribuição do valor adicionado. Empresas de capital aberto com sede no Brasil - 2008 a 2016

Fonte: Autores.

No Gráfico 1, fica ainda mais perceptível a supremacia do Governo em relação à apropriação da riqueza. No período de 2008 a 2011, percebe-se que as proporções de distribuição entre Trabalho e Capital - próprio e de terceiros - foram menos variáveis. Outra percepção importante trazida pela plotagem é a relação inversa e quase que simétrica entre Capital Próprio e de Terceiros na distribuição do VA. Sobre essa relação, trazendo a análise para nível de demonstrativos financeiros, o EBITDA dessas empresas, indicador que revela a capacidade operacional de uma empresa em "gerar caixa", pode não ter sido suficiente para arcar com as despesas de juros e amortizações do principal da dívida, que sofreram aumentos. Esse fenômeno já vinha sendo constatado em companhias brasileiras de capital aberto (FRAGA; CARNEIRO, 2016; VALLE 2016; ECONOMATICA, 2017) e pode, assim, ter comprometido a geração de lucros disponíveis para a distribuição de dividendos e a retenção pelas empresas, que, como observado na distribuição do VA, veio reduzindo e teve déficit em 2015.

Adicionalmente, cabe ainda ressaltar que os padrões distributivos apurados aqui, a partir das DVAs, se diferem de padrões apurados em países centrais, como os do Reino Unido. Nesses países, percebe-se uma enorme discrepância nas distribuições, quando comparados ao Brasil, principalmente nas parcelas distribuídas aos empregados, que são os maiores beneficiários, e na destinação ao Governo, que ocupa as últimas colocações (SALES; BATISTA; THEÓPHILO, 2018). Essas evidências dão indícios empíricos da superexploração 
do trabalho em países periféricos, além da transferência do valor agregado ao capital via financiadores externos e Governo, visto que parte do orçamento público brasileiro é destinada ao pagamento de juros e amortizações da dívida pública. Isso reafirma o ciclo do capital de economia dependente no Brasil.

\subsection{Análise de correlação}

Para avaliar o grau de associação entre o valor adicionado e as suas distribuições, foi calculado o coeficiente de correlação de Pearson para cada uma dessas variáveis. Nessa análise, foram utilizadas as representações percentuais de distribuição a cada agente econômico em relação ao valor adicionado, e não seu valor absoluto em unidade monetária, a fim de relativizar a análise e reduzir diferenças de escala. Sendo assim, publicações de valor adicionado negativo encontradas em 39 observações (vide Tabela 1) estariam influenciando, de forma individual, as variáveis relativizadas, invertendo o seu sinal (com numerador e denominador negativos). Dessa forma, especialmente para essa estimação, foram excluídas da amostra 28 empresas responsáveis por publicar, em algum momento, valor adicionado negativo, permanecendo 1737 observações - $193 \times 9$. Em seguida, com os valores adicionados estritamente positivos e a fim de reduzir o excesso de assimetria e curtose para essa variável, foi feita a sua transformação em logaritmo, como sugerem Fávero et al. (2014), para casos semelhantes de variáveis com medidas de grande escala. Feitos os devidos ajustes, é apresentada a Tabela 3, com a matriz de correlação das variáveis supracitadas:

Tabela 3 - Correlação entre o valor adicionado e as proporções percentuais de sua distribuição para cada agente econômico. Empresas selecionadas - 2008 a 2016

\begin{tabular}{crrrrr}
\hline & \multicolumn{1}{c}{$\boldsymbol{l}$ logVA } & \multicolumn{1}{c}{ PPES } & PGOV & PTER & PPRO \\
\hline logVA & 1 & & & & \\
PPES & $\mathbf{- 0 , 4 1 1 8}$ & 1 & & & \\
$\rho$-valor & 0,000 & & & & \\
PGOV & $\mathbf{0 , 1 2 0 3}$ & $\mathbf{- 0 , 0 3 4 1}$ & 1 & & \\
$\rho$-valor & 0,000 & 0,1555 & & & \\
PTER & $\mathbf{- 0 , 0 9 1 2}$ & $\mathbf{0 , 2 0 8 2}$ & $\mathbf{- 0 , 2 4 9 0}$ & & \\
$\rho$-valor & 0,000 & 0,000 & 0,000 & & \\
PPRO & $\mathbf{0 , 2 1 9 5}$ & $\mathbf{- 0 , 6 5 5 1}$ & $\mathbf{- 0 , 2 0 4 4}$ & $\mathbf{- 0 , 6 3 7 8}$ & \\
$\rho$-valor & 0,000 & 0,000 & 0,000 & 0,000 & \\
\hline
\end{tabular}

Notas: $\log$ VA - Logaritmo do Valor Adicionado; PPES - Participação de pessoal; PGOV - Participação do Governo; PTER - Participação do capital de terceiros; PPRO - Participação do capital próprio.

Fonte: Autores. 
Segundo Wooldrigde (2013), o log de valores monetários positivos é frequentemente utilizado. Tomar o logaritmo de uma variável permite mitigar, ou até mesmo eliminar, problemas de heterocedasticidade e assimetria, além de estreitar sua amplitude - fato que "é particularmente verdadeiro em variáveis que podem assumir grandes valores monetários" (WOOLDRIGDE, 2013, p. 193).

Percebeu-se que, apesar de significantes estatisticamente $(\rho<0,000)$, com exceção da correlação entre "PGOV" e "PPES", essas correlações se apresentam com força moderada $(0,4<\mathrm{r}<0,7)$, fraca $(0,2<\mathrm{r}<0,4)$ e muito fraca $(0,0<\mathrm{r}<0,2)$ (com coeficientes positivos ou negativos, situando-se entre os limites de $-1 \leq \mathrm{r} \leq 1$ ) (MARTINS; THEÓPHILO, 2016). A priori, na primeira coluna da matriz, é realizada a análise de correlação do valor adicionado com as suas parcelas de distribuição. Nessa faixa, os resultados indicam que existe uma relação inversa entre o valor adicionado e a participação de pessoal (PPES) na sua apropriação. Em outras palavras, é válido dizer que, na medida em que a riqueza gerada pelas empresas aumenta, a participação dos trabalhadores nessa geração diminui, ou vice-versa. Verifica-se, também, que essa correlação se apresenta com força moderada, indicando média associação linear entre essas duas variáveis $(-0,41)$.

Já as correlações entre o valor adicionado e a participação do governo (PGOV) e do valor adicionado e a participação de capital de terceiros (PTER) são muito fracas, apuradas com sinal positivo para a primeira e negativo para a segunda. Isso indica baixo grau de associação linear entre o valor adicionado e a apropriação para esses dois agentes.

No que diz respeito à última correlação dessa coluna, entre o valor adicionado e a participação de capital próprio em sua distribuição (PPRO), verifica-se uma associação linear fraca em sentido positivo, revelando que essas variáveis têm baixa relação, ainda que estatisticamente significante. Assim, pode-se dizer, de forma geral, que aumentos na riqueza gerada pelas empresas terão acompanhamento de maiores proporções na apropriação pelos empresários, com lucros distribuídos e retidos pelas empresas. Esse comportamento é contrário ao que se observa na relação entre o VA e a sua distribuição aos trabalhadores, que, por sua vez, se apropriam de uma menor fatia na medida em que a riqueza gerada na esfera produtiva aumenta.

Seguindo na análise das correlações, também são mostrados, na Tabela 3, os graus de associação das participações dos agentes econômicos no VA entre si. Dessas, percebe-se maior destaque das relações entre participação de capital próprio e participação de pessoal, e entre participação de capital próprio e participação de capital de terceiros, ambos os coeficientes apurados em sentido negativo e de força moderada $(-0,65$ e $-0,64$, 
respectivamente). Verifica-se que esses coeficientes são os de maior grandeza numérica dentre os demais, o que sugere uma maior sensibilidade na apropriação do fator capital próprio em relação aos demais componentes na distribuição do VA. Em outras palavras, isso indica que os aumentos na apropriação da renda pelas demais classes se associam a menores parcelas destinadas ao capital próprio. Isto se deve à natureza residual do lucro do capital próprio, o qual deve ser "reivindicado" pelos seus donos, conhecidos nesse sentido por "Residual Claimants", apenas na existência de lucro disponível, o que lhes é de direito.

Uma relação negativa entre a participação do capital próprio e a participação do pessoal também foi apurada por Vieira (2010), entretanto, aplicando a correlação ordinal de Spearman.

Esta análise de correlações respalda a evolução da distribuição do valor adicionado trazido pelo Gráfico 1, em que se visualiza esse comportamento ao longo do tempo, o qual é influenciado pela conjuntura econômica, que irá definir exigências de alocação da renda entre os agentes.

\section{CONSIDERAÇÕES FINAIS}

A evidenciação, por intermédio da DVA, da distribuição da riqueza entre os agentes econômicos promove um avanço da classe empresarial (a priori, detentora dessas informações e, agora, responsável por divulgá-las) na sua relação com os demais: Governo, Financiadores externos e os Trabalhadores. A forma como essas informações vem sendo divulgadas, periodicamente à disposição dos usuários e no nível da firma, possibilita o desenvolvimento de trabalhos como este, a fim de entender melhor o processo do desenvolvimento econômico e, concomitantemente, como alcançar o crescimento econômico igualitário, em meio aos avanços tecnológicos e às crises da economia.

Este estudo se mostra relevante, pois, para o alcance do seu propósito, combina elementos das Ciências Contábeis e das Ciências Econômicas, promovendo um novo ponto de vista sobre a distribuição funcional da renda, a partir das maiores empresas de capital aberto do Brasil. Assim, contribui para a formalização de um padrão nas pesquisas nessa área, considerando as pesquisas anteriores no Brasil - país referência nessa área, em função, principalmente, do incentivo e da obrigatoriedade da divulgação da DVA no país.

Foi proposto aqui analisar, por meio da DVA, como a riqueza gerada foi distribuída entre os agentes e, com isso, identificar padrões de comportamento dessa distribuição com foco nas inter-relações entre esses agentes. Com destaque nessa conjuntura analisada, o fator 
trabalho recebeu ligeiros aumentos, o que diferiu dos achados de Cunha (2002) e Cunha, Ribeiro e Santos (2005), na conjuntura analisada no período de 1996 a 2003. Na análise desses pesquisadores, a riqueza destinada aos empregados sofreu reduções consideráveis, atreladas ao aumento médio do número de contratações, o que contribuiu ainda mais para a redução do valor adicionado distribuído ao pessoal, quando divido pelo número de empregados. Nesse contexto, uma limitação deste estudo foi não ter considerado o indicador "valor adicionado por empregado", o qual figura na edição da Revista Exame "Melhores e Maiores" e é amplamente utilizado em outros estudos da mesma linha (SANTOS, 1999; CUNHA, 2002; CUNHA; RIBEIRO; SANTOS, 2005; VIEIRA, 2010; WINK, 2014).

Ao se analisar a evolução da distribuição do valor adicionado entre os agentes, ficou perceptível a relação inversa e quase simétrica (relação gráfica) entre as parcelas para capital próprio e para o capital de terceiros, principalmente. A conjuntura do período analisado, que foi favorável ao endividamento excessivo das empresas, contribuiu para que a destinação da riqueza aos financiadores externos entrasse em ascensão, ao contrário da destinação aos empresários, que, nesse período, entrou em severa recessão.

$\mathrm{Na}$ análise de correlações, os resultados mostraram haver correlação negativa (com força moderada) entre o valor adicionado e a participação (\%) do pessoal, indicando que aumentos no valor adicionado podem estar acompanhados de reduções da sua distribuição relativa aos trabalhadores na forma de salários. Em relação à associação entre as próprias participações $(\%)$ dos agentes econômicos no VA, os destaques de maior grandeza numérica foram das relações entre a participação do capital próprio e participação do pessoal e entre a participação do capital próprio e a participação do capital de terceiros - ambos coeficientes de correlação apurados em sentido negativo e com força moderada. Isto sugere a existência de uma maior sensibilidade da parcela do capital próprio nas relações com as outras classes explicadas, principalmente pela natureza residual da remuneração do capital próprio, que teria direito de "reivindicar" (claim) a sua parte apenas na ocorrência do lucro, depois de supridas as exigências sobre o valor adicionado das empresas.

Algo a se considerar para novos estudos seria a extensão do número de empresas na amostra para uma pesquisa em um novo intervalo de tempo, em anos mais recentes, pois se acredita que mais empresas vêm divulgando regularmente as suas demonstrações contábeis, principalmente a partir de 2010, com a padronização das normas de contabilidade pela IFRS. Apesar de essas normas internacionais não tornarem compulsiva a divulgação da DVA, incentivam a sua publicação. Outra sugestão seria a análise conjunta das informações prestadas aqui com as informações das contas nacionais divulgadas pelo IBGE. Como 
salientam Cunha, Ribeiro e Santos (2005), para que essa comparação seja satisfatória, as normas de elaboração da DVA ainda precisam se adaptar às necessidades dos usuários, indicando, por exemplo, o Estado e a região onde aquela riqueza foi gerada, ou parte dela, visto que uma empresa com sede em um determinado Estado pode possuir várias unidades fora deste. Outra possibilidade de estudos seria a realização desta análise estratificada por setor econômico, o que apontaria diferenças entre padrões distributivos quando comparados entre os setores.

\title{
ANALYSIS OF THE DISTRIBUTIVE PATTERNS OF WEALTH IN BRAZIL FROM PUBLICLY TRADADED COMPANIES - 2008 to 2016
}

\begin{abstract}
The disclosure, through Value-Added Statement (VAS) of wealth share among different classes of society promotes an advance of the business class in its relation with the other classes such as Government, external financiers and the general population. Within this context, adopting an empirical-analytic investigation of the accounting reports of 221 corporations, this work had the general purpose of analyzing through the VAS, the distributive patterns of the wealth generated among economic agents Workers, Government, Financiers and Shareholders of Brazilian non-financial public companies, from 2008 to 2016. In this analysis an inverse and almost symmetric relationship (graphical relation) between the capital and third-party capital, especially, was perceptible. Regarding correlations analysis, the results of the calculated coefficients statistically support the relationship between these variables, mainly with concern to the capital-labor relationship verified in negative signal with moderate force. This study is relevant, since it combines elements of Accounting Sciences and Economic Sciences, promoting a new point of view on the functional distribution of income from the largest publicly traded companies in Brazil, responsible for much of the wealth generated in national scope.
\end{abstract}

Keywords: Value added Statement. Distribution of wealth. Indebtedness.

\section{REFERÊNCIAS}

BRESSER-PEREIRA, Luiz. Carlos. O conceito histórico de desenvolvimento econômico. São Paulo, Fundação Getúlio Vargas - EESP, 1-24, 2006.

COMITÊ DE PRONUNCIAMENTOS CONTÁBEIS (CPC). CPC 00 (R1), de 15 dez. 2011. Estrutura Conceitual para Elaboração e Divulgação de Relatório Contábil-Financeiro. Brasília-DF, 2011. Disponível em: http://www.cpc.org.br/CPC/DocumentosEmitidos/Pronunciamentos/Pronunciamento?Id=80 
CUNHA, Jacqueline Veneroso Alves; RIBEIRO, Maisa de Souza; SANTOS, Ariovaldo dos. A demonstração do valor adicionado como instrumento de mensuração da distribuição da riqueza. Revista Contabilidade \& Finanças. São Paulo, n. 37, p. 7-23, 2005.

CUNHA, Jaqueline Veneroso Alves. Demonstração contábil do valor adicionado - DVA um instrumento de mensuração da distribuição da riqueza das empresas para os funcionários. 2002. 207 f. Dissertação (Mestrado em Controladoria e Contabilidade) - Faculdade de Economia, Administração e Contabilidade da Universidade de São Paulo São Paulo, 2002.

DE LUCA, Márcia Martins Mendes. A contribuição da demonstração do valor adicionado no processo de mensuração do PIB e em algumas análises macroeconômicas. 1996. $153 \mathrm{f}$. Tese (Doutorado em Ciências Contábeis) - Programa de Pós-Graduação em Ciências Contábeis, Faculdade de Economia, Administração e Contabilidade da Universidade de São Paulo. São Paulo, 1996.

. Demonstração do valor adicionado. 1991. 121 f. Dissertação (Mestrado em Ciências Contábeis) - Programa de Pós-Graduação em Ciências Contábeis, Faculdade de Economia, Administração e Contabilidade da Universidade de São Paulo. São Paulo, 1991.

ECONOMATICA®. A dívida das empresas de capital aberto no $3^{\circ}$ trim. de 2017 registra queda com relação ao trimestre anterior e volta a níveis de março de 2015. On-line, 2017. Disponível em http://economatica.com/estudos.html. Acesso em: 30 nov 2017.

EMPRESA DE PESQUISA ENERGÉTICA - EPE. Anuário estatístico de energia elétrica 2016: ano base 2015. Brasília: Ministério de Minas e Energia, 2016. Disponível em: http://www.epe.gov.br/AnuarioEstatisticodeEnergiaEletrica/Forms/Anurio.aspx. Acesso em: 05 set. 2017.

FÁVERO, Luiz Paulo et al. Métodos quantitativos com stata®. Rio de Janeiro: Elsevier, 2014.

FRAGA, Érica; CARNEIRO, Mariana. Asfixia financeira das empresas ameaça recuperação da economia. Folha de São Paulo, São Paulo: Caderno mercado, p. 6, domingo, 7 ago. 2016.

FREGONESI, Mariana Simões Ferraz do Amaral. Investimentos socioambientais na demonstração do valor adicionado: formação ou distribuição do valor adicionado? 2009. 229 f. Tese (Doutorado em Controladoria e Contabilidade: Contabilidade) Programa de PósGraduação em Controladoria e Contabilidade, Faculdade de Economia, Administração e Contabilidade, Universidade de São Paulo, São Paulo, 2009.

FURTADO, Celso. Desenvolvimento e subdesenvolvimento. Rio de Janeiro: Fundo de Cultura, 1961. 
HALLAK NETO, João; SABOIA, João. Distribuição funcional da renda no Brasil: análise dos resultados recentes e estimação da conta da renda. Economia Aplicada, Ribeirão Preto, v. 18, n. 3, p. 483-513, 2014.

LONDERO, Paola Richter; BIALOSKORSKI NETO, Sigismundo. Demonstração do valor adicionado como instrumento de evidenciação do impacto econômico e social das cooperativas agropecuárias. Organizações Rurais \& Agroindustriais, Lavras, v. 18, n. 3, p. 256-272, 2016.

LORANDI, Joisse Antônio; ALEXANDRE, Ciaclei Luca. Demonstração do valor adicionado: um estudo bibliométrico nas revistas nacionais de contabilidade constantes no portal da capes. In: V Congresso ANPCONT. Anais... Vitória, 2011.

MACHADO, Márcia Reis. As informações sociais e ambientais evidenciadas nos relatórios anuais das empresas: a percepção dos usuários. 2010. 168 f. Tese (Doutorado em Controladoria e Contabilidade: Contabilidade) - Programa de Pós-Graduação em Ciências Contábeis, Faculdade de Economia, Administração e Contabilidade, Universidade de São Paulo, São Paulo, 2010.

MACHADO, Márcio André Veras; MACEDO, Marcelo Álvaro da Silva; MACHADO, Márcia Reis. Análise da relevância do conteúdo informacional da DVA no mercado brasileiro de capitais. Revista Contabilidade \& Finanças, São Paulo, v. 26, n. 67, p. 57-69, 2015.

MARTINS, Eliseu; MIRANDA, Gilberto José; DINIZ, Josedilton Alves. Análise didática das demonstrações contábeis. 2. ed. São Paulo: Atlas. 2018.

MARTINS, Gilberto de Andrade; THEÓPHILO, Carlos Renato. Metodologia da investigação científica para ciências sociais aplicadas. 3. ed. São Paulo: Atlas, 2016.

MORAES, Pérsio Belluomini. Uso da demonstração do valor adicionado (DVA) como ferramenta de mensuração dos tributos de empresas selecionadas no Brasil. 2008. $193 \mathrm{f}$. Dissertação (Mestrado em Gestão de Negócios) - Programa de Pós-Graduação em Gestão de Negócios, Universidade Católica de Santos, Santos, 2008.

MORCH, Rafael Borges; ALMEIDA, Esmael; ALMEIDA, Lauro Brito de; MARQUES, José Augusto Veiga da Costa. A demonstração do valor adicionado como instrumento de análise do impacto tributário para empresas do setor elétrico. RIC - Revista de Informação Contábil, Recife, v. 2, n. 4, p. 1-16, 2008.

MORLEY, Michael Francis. The Value Added Statement in Britain. Accounting Review, Sarasota, v. 54, n. 3, p. 618-629, 1979.

SALES, Handerson Leonidas; BATISTA, Alexandre Teixeira Norberto; THEÓPHILO, Carlos Renato. Teoria da Dependência: um estudo da interlocução dos pensamentos de Ruy Muro Marini com a realidade empírica brasileira. In: VI Congresso em Desenvolvimento 
social: Desafios a Democracia, Desenvolvimento e Bens Comuns. Anais... Montes Claros: UNIMONTES, 2018.

SANTOS, Ariovaldo dos. Demonstração contábil do valor adicionado - DVA: um instrumento para medição da geração e distribuição de riqueza das empresas. 1999. Tese (Livre Docência) - Programa de Pós-Graduação em Ciências Contábeis. Faculdade de Economia, Administração e Contabilidade da Universidade de São Paulo, São Paulo, 1999.

Demonstração do valor adicionado: como elaborar e analisar a DVA. São Paulo, Atlas, 2003.

SANTOS, Ariovaldo dos et al. The economy of companies in the FHC and Lula governments: An analysis based on Value Added Statements. Revista Contabilidade e Controladoria-RC\&C, v. 5, n. 1, p. 47-64, 2013.

SANTOS, Ariovaldo dos; HASHIMOTO, Hugo. Demonstração do valor adicionado: algumas considerações sobre carga tributária. Revista de Administração, São Paulo, v. 38, n. 2, p. 153-164. 2003.

SCARPIN, Jorge Eduardo; DE LUCA, Márcia Martins Mendes; CUNHA, Jacqueline Veneroso Alves da; DALLABONA, Lara Fabiana. Valor adicionado e lucratividade das empresas listadas na Revista Exame Maiores e Melhores no período de 2007-2010. In: XXXVI EnANPAD. Anais ... Rio de Janeiro, 2012.

SCHERER, Luciano Márcio. Valor adicionado: análise empírica de sua relevância para as companhias abertas que publicam a demonstração do valor adicionado. 2006. 139f. Tese (Doutorado em Controladoria e Contabilidade: Contabilidade) - Programa de Pós-Graduação em Ciências Contábeis, Faculdade de Economia, Administração e Contabilidade, Universidade de São Paulo, São Paulo, 2006.

SILVA, Manoel Rubim da; MARQUES, Mary Amália Castro Rocha. Demonstração do valor adicionado (DVA): um instrumento para aferição da carga tributária por unidade ou segmentos produtivos. Revista da Receita Federal: estudos tributários e aduaneiros, Brasília, v. 1, n. 2, p. 217-232, 2015.

TEODORO, Jocelino Donizetti; CATAPAN, Anderson; BARROS, Claudio Marcelo Edwards; SCHERER, Luciano Márcio. Valor adicionado: tendência metodológicas e temáticas adotadas no período de 1970-2010. Revista Ambiente Contábil, Natal, v. 4, n. 2, p. 132-148, 2012.

TINOCO, João Eduardo Prudêncio. Balanço social: uma abordagem sócio-econômica da contabilidade. 1984. Dissertação (Mestrado em Contabilidade e Controladoria) - Programa de Pós-Graduação em Ciências Contábeis, Faculdade de Economia e Administração da Universidade de São Paulo, São Paulo, 1984. 
TINOCO, João Eduardo Prudêncio; MORAES, P.B.; PELEIAS, I. R.; CLARO, J. A. C. S.; JOAO, B. N. Estudo sobre a carga tributária de empresas brasileiras através da demonstração do valor adicionado (DVA) - período de 2005 a 2007. Revista Ciências Administrativas Fortaleza, v. 17, p. 84-111, 2011.

VALLE, Patrícia. Empresas brasileiras vivem para pagar juros. Exame. São Paulo, v. 1117, n. 14, p. 42-47, 2016.

VIEIRA, Patrícia dos Santos. Verdades e mitos na interpretação da demonstração do valor adicionado. 2010. 152f. Dissertação (Mestrado em Controladoria e Contabilidade: Contabilidade) - Programa de Pós-Graduação em Ciências Contábeis, Faculdade de Economia, Administração e Contabilidade, Universidade de São Paulo, São Paulo, 2010.

WINK, Eduardo. A distribuição de riqueza ao capital e ao trabalho em entidades brasileiras por meio da demonstração do valor adicionado - DVA - no período de 2008 a 2012. 2014. 168f. Dissertação (Mestrado em Ciências Contábeis) - Programa de PósGraduação em Ciências Contábeis, Universidade do Vale do Rio dos Sinos, Programa de PósGraduação em Ciências Contábeis, São Leopoldo, 2014.

WOOLDRIGDE, Jeffrey Marc. Introductory Econometrics: a modern approach. 5. ed. Boston: Cengage Learning, 2013.

\section{DADOS DOS AUTORES}

\section{Alexandre Teixeira Norberto Batista}

E-mail: alexandretnb@yahoo.com.br

Currículo Lattes: http://lattes.cnpq.br/7968579030517122

Mini currículo: Mestre em Desenvolvimento Econômico e Estratégia Empresarial pela Universidade Estadual de Montes Claros. MBA em Gestão Financeira, Controladoria e Auditoria pela Fundação Getúlio Vargas. Bacharel em Administração pela Universidade Federal de Minas Gerais.

\section{Wagner de Paulo Santiago}

E-mail: wapasan@gmail.com

Currículo Lattes: http://lattes.cnpq.br/6518303056388945

Mini currículo: Doutor em Administração pela Universidade Federal de Minas Gerais. Professor no Departamento de Ciências Contábeis da Universidade Estadual de Montes Claros.

\section{Luiz Antonio de Matos Macedo}

E-mail: matos-macedo@uol.com.br

Currículo Lattes: http://lattes.cnpq.br/4815622554406699

Mini currículo: Doutor em Economia pela University College da Universidade de Londres. Professor no Departamento de Ciências Econômicas da Universidade Estadual de Montes Claros. 